\title{
INDIAN PEDIATRICS ON FACEBOOK
}

Indian Pediatrics (IP) Facebook page is an online community through which IP aims to connect fellow pediatricians, reach beyond the pediatric community to others interested in improving child care, create conversations about issues in pediatric education, national policies, and share news. The IP Facebook page was officially launched on 5th March 2014.

How to Become an IP Facebook Follower/Fan?

Log into your Facebook profile, and search 'Indian Pediatrics.' Alternatively, visit the URL: https:// www.facebook.com/IndianPediatrics. In the Indian Pediatrics Facebook page, click 'Like'; you are now connected with IP on Facebook! Once you become follower/fan of a Facebook page, you are connected with the organization, and will receive news updates of the Facebook page in your own newsfeed.

In just five days, the Facebook page of Indian Pediatrics had reached 1000 likes.

Number offollowers: 1265 (as on 18 th March 2014)

Number of countries of origin of followers : 21

People's Voice

Such a great initiative... congrats to the whole team 4 the launch.. hope tat this facebook page will now be a new gateway for open discussion ... and of course 4 learning purpose 4 the juniors like me... $\mathrm{n} \mathrm{m}$ also really glad to get the title of" the 1000th fan".... thank $u$ all and looking forward 4 the best... Radhapyari Lourem

Happy to see this development...Lot of people after reading articles want to discuss more.. May be appreciations, may be disagreements on points, may be contribute additional points. But it was not easy...I hope this will be a good platform to have good discussions of articles in IP...Hope the authors of articles also will be invited for the discussion...P Kuzhikkathukandiyil

Always amazed by the strides made by the journal. Congrats to you and all those who are working tirelessly behind the success of this excellent publication. From strong roots do strong trees grow, and we are indebted to all those who came before us, planting the seed, watering and nurturing it and taking it to the heights that we see it at now...Taher Kagalwala

IP is one of the most reliable compendium for practicing pediatricians. Starting up of Facebook page is another feather in its cap. Thanks to IP team.... Sanjeev Aggarwal

Congratulations and thanks for making this world class journal known to every one on FACEBOOK!... Shyam Sidana

This Facebook idea is wonderful, practical and effective in percolating simple child health messages through masses. I wish its longevity and regularity...RK Agarwal (Former President IAP)

The physical qualities of the Journal (quality of printing, paper, art work etc) need a great deal of improvement...Rajendra Srivastava

Worth spending time out of busy schedule ... Vinod Kumar

IP wants this page not only a place to post information about our journal articles, but a place where our readers can come together, discuss new ideas, and debate each other. We welcome feedback, complaints, recommendations, and other comments.

Thank you all for your love and support.

Editorial Team Indian Pediatrics 